\title{
Effect of electromagnetic waves on human reproduction
}

\author{
Artur Wdowiak', Paweł A. Mazurek², Anita Wdowiak', Iwona Bojar ${ }^{3}$ \\ ${ }^{1}$ Diagnostic Techniques Unit, Medical University of Lublin, Poland \\ ${ }^{2}$ Institute of Electrical Engineering and Electrotechnologies, University of Technology, Lublin, Poland \\ ${ }^{3}$ Institute of Rural Health, Lublin, Poland
}

Wdowiak A, Mazurek PA, Wdowiak A, Bojar I. Effect of electromagnetic waves on human reproduction. Ann Agric Environ Med. 2017; 24(1): 13-18. doi: 10.5604/12321966.1228394

\begin{abstract}
Electromagnetic radiation (EMR) emitting from the natural environment, as well as from the use of industrial and everyday appliances, constantly influence the human body. The effect of this type of energy on living tissues may exert various effects on their functioning, although the mechanisms conditioning this phenomenon have not been fully explained. It may be expected that the interactions between electromagnetic radiation and the living organism would depend on the amount and parameters of the transmitted energy and type of tissue exposed. Electromagnetic waves exert an influence on human reproduction by affecting the male and female reproductive systems, the developing embryo, and subsequently, the foetus. Knowledge concerning this problem is still being expanded; however, all the conditionings of human reproduction still remain unknown. The study presents the current state of knowledge concerning the problem, based on the latest scientific reports.
\end{abstract}

\section{Key words}

human reproduction, electromagnetic waves, infertility, exposure to electromagnetic fields

\section{INTRODUCTION}

Reproductive disorders affect an increasing number of marriages. The obtaining of pregnancy and the health state of the baby depend on the quality of the genetic material of both the male and the female. Male fertility is influenced by many environmental factors, including heavy metals, air pollution, plant protection products and electromagnetic waves.

An electromagnetic field (also EMF) can be viewed as the combination of an electric field and a magnetic field; therefore, both components are important in the analysis of exposure. Electromagnetic radiation consists of electromagnetic waves, which are synchronized oscillations of electric and magnetic fields that propagate through a vacuum at the speed of light. Electromagnetic waves are a form of radiation within the range from ultra high-energy cosmic rays and gamma rays with frequencies of $10^{18} \mathrm{~Hz}$ to low-energy microwave radiation of $10 \mathrm{GHz}$, or radio waves of $100 \mathrm{MHz}$. As a result, an electromagnetic field is generated. These forms of energy may affect the functioning of living organisms; however, knowledge about this problem is still insufficient. Recent years have brought many reports concerning the problem of the effect of radio frequencies on human health, seeking in them both positive and negative effects.

Energy carried by electromagnetic radiation is absorbed into the living tissue, i.e. converted into kinetic energy of the particles of which the object is constructed. The amount of electromagnetic radiation absorbed per mass within a specified time is defined as the Specific Absorption Rate (SAR). This value is a basis for determination of the maximum allowable intensities of the electromagnetic fields

Address for correspondence: Artur Wdowiak, Diagnostic Techniques Unit, Medical University of Lublin, Staszica 4-6, 20-081 Lublin, Poland

E-mail:wdowiakartur@gmail.com

Received: 21 January 2016; accepted: 23 August 2016; first published on December, 2016 energy streams to which a human body may be exposed. The allowable SAR values are specified for various parts of the body. There is also a mean SAR value defined for the whole body:

$$
S A R=\frac{\sigma \cdot E^{2}}{\rho} \quad[\mathrm{W} / \mathrm{kg}]
$$

where: $\sigma$ - electric conductivity of the sample (tissue) in $\mathrm{S} / \mathrm{m}, E$ - value of electric field strength in $\mathrm{V} / \mathrm{m}, \rho$ - density of the sample in $\mathrm{kg} / \mathrm{m}^{3}$.

The energy absorbed in the tissues of the living body may cause an increase in its temperature, especially within high frequencies fields. In normal conditions, the absorbed energy of the values $\mathrm{SAR}=4 \mathrm{~W} / \mathrm{kg}$ causes an increase in the body temperature of a healthy individual by $1^{\circ} \mathrm{C}$. Studies demonstrated that such a dose does not cause any negative health effects. Restrictions with respect to the SAR are the basic restrictions which means that the values of the coefficient should not be exceeded under any circumstances. At the heart of international protective recommendations, also in Poland, lays the conviction that restriction of the allowable SAR value to $0.4 \mathrm{~W} / \mathrm{kg}$ for the whole body, on average, should provide a sufficient margin of safety for occupational exposure at the workplace. For environmental exposure (total population), an additional safety coefficient is adopted equal to 5, i.e. the allowable SAR value is restricted to $0.8 \mathrm{~W} / \mathrm{kg}$. Restriction of the whole body SAR value does not constitute sufficient protection against an excessive local absorption of energy which might lead to local overheating; therefore, restrictions of the highest locally allowable SAR values are additionally introduced. One of the methods of analysis of the SAR coefficient is the FDTD method (Finite Difference Time Domain), which consists in the construction of a discrete model of the examined object, and solution by the method of finite difference Maxwell's equations describing the object in the time domain [1]. 
Polish legislation specifies allowable electric and magnetic field strength values of the frequency of $50 \mathrm{~Hz}$ and from 0.001 $-300 \mathrm{MHz}$, as well as a power density within the frequencies of $0.3-300 \mathrm{GHz}$. In the areas surrounding the sources of electromagnetic fields, where the values of the mean microwave power density $0.1 \mathrm{~W} / \mathrm{m}^{2}$ are exceeded of the electromagnetic radiation within the frequencies $0.3-300 \mathrm{GHz}$, the presence of humans is prohibited, except for those employed with the exploitation of these fields. The electric field strength of the frequency of $50 \mathrm{~Hz}$ cannot exceed the value of $1 \mathrm{kV} / \mathrm{m}$ in areas of housing development, and in areas where hospitals, nurseries, kindergartens, and boarding houses are located. The values of the SAR for humans change in the function of the frequency of electromagnetic radiation [1].

Electromagnetic waves exert an influence on human reproduction by affecting the male and female reproductive system, the developing embryo, and subsequently, the fetus. Knowledge of this problem is still being expanded, although all the conditionings of human reproduction still remain unknown. EMF and EMR related studies were specified by peer-reviewed literature and data searched for in an electronic database (PubMed) using a number of key words and their combinations (electromagnetic field, electric, magnetic, reproductive outcome, semen and infertility) in order to find English-language reports related to the effect of electromagnetic waves on human reproduction.

Mechanisms of the effect of EMR. In the electric field, opposite electric charges shift in opposite directions and their polarization takes place; however, this does not concern only free charges which sporadically occur in the living tissue. Polarization also takes place in the particles in which the total electric charge is equal to zero. As a result of polarization in this type of particles, electric dipoles are induced. In an alternating electric field we deal with a constant repolarization of dipoles, an energy-consuming phenomenon which generates the absorption of the energy of the electric field. Living tissue contains large amounts of water, the particles of which are permanent electric dipoles. In the alternating electric field, dipoles perpetually vibrate around their own axis, contributing to the absorption of electric energy [1].

There are many hypotheses which may explain the effect of RF EMR in the biology of reproduction. The emission of high power electromagnetic waves may contribute, among other things, to an increase in the temperature of the tissues, whereas RF EMR of a low level, lower than that required for the direct ionization of a particle, may cause biochemical effects. It may be presumed that basically, all possible mechanisms concerning the coherence, resonance, signal averaging, heterogeneity of the magnetic field in heterogenous dielectric structures and non-linear effects, generate signals of a power much lower than magnetic fields related with normal physiological functions of physiological healing of wounds, stimulation of the muscles and functioning of the nervous system [2]. Challis recognized one probable non-thermal process: formation of free radicals in biomolecules with large hypersubtle structures and rapid magnetic relaxation [3]. Energy from the external signal may be concentrated in this process when the electromagnetic wavelength is equal to the difference between energy levels in the molecule, which leads to an increase in signal strength forcing. However, the force of signal strengthening decreases with the loss within the system. The majority of ions are bonded to water; therefore, the dispersion of energy while hitting water particles increases the loss of the system with radio frequencies, limiting the degree of strengthening which might be achieved in the resonance systems.

One of the concepts frequently used to justify the effect exerted by radio waves on the cells is the induction of additional potentials on cellular membranes, which interfere with the transport of ions [4]. The change of ions transport via the cellular membrane is possible, but only in the case of fields with a voltage of several hundred micro-volts, considerably higher than the voltages generated physiologically by the membranes of organelles, such as mitochondria. Exposure to non-physiological voltage of the whole cell organelles showed that when the membrane of a given structure is thicker than the cellular membrane and organelles contain higher concentrations of ions, more energy passes through the organelle membrane than through the cellular membrane [4].

The subsequent concept often used to justify the effect of radio waves on cells is the induction of changes in molecular bonds, which may affect the activity of protein enzymes [5]. According to Cotgreave, the structure of cellular proteins is diverse, and it may be expected that exposure to RF will be able to exert an effect according to the structure of protein [5]. In addition, many proteins are electrostatically bound, thus, RF EMR may affect the protein structures within a cell. Scientific studies have demonstrated that the denaturation, aggregation and stability of proteins are susceptible to the effect of radio waves $[6,7]$. In fact, the efficacy of protein as an enzyme depends on its structure. Some side chains of amino acids in proteins are polar, and will behave differently during exposure to the EMR. Experiments with a high level of radiation (for the frequency band from $1.95 \mathrm{GHz}$ ) showed an effect on the packaging of proteins [8]. Thus, the possible physical models suggest that the interaction between charge and dipols in each protein structure change the level of barrier for the processes of packaging of proteins in metabolic pathways [8].

EMR and the male reproductive system. The male reproductive system is a group of tissues very sensitive to external factors, and sperm which does not possess the capability of repair of its genetic material, and for this reason seems to be vulnerable to various kinds of damage generated by external factors. The literature reports to-date concerning the problem of the effect of electromagnetic waves on male reproductive cells are unequivocal. The example are many studies analyzing the amount of time devoted to conversations by cellular phone, which do not consider a totally different life style and character of work of people who are excessively exposed to the waves of the GSM band. In this case, one may wonder whether the results of the studies obtained are more affected by electromagnetic waves or the character of work performed, or perhaps work-related stress. The second type of reports are based on the analysis of exposure of sperm to specified frequencies outside the human body, which excludes the effect of other factors; however, they do not imitate in vivo conditions.

Based on studies conducted by Agarwal et al., it is known that EMR induces oxidative stress and causes disorders in the sperm mitochondria and activation of NADH oxidase of the cellular membrane [9]. Oxidative stress also exposes sperm to the loss of motility and capability of combining with 
the egg cell. Disorders in the oxidoreductive system cause lipid peroxidase and free radical process of oxygenation of unsaturated fatty acids in the cellular membrane. Also, sperm chromatin is exposed to the negative effects of oxidative stress, which is subject to fragmentation, and the process of formation of DNA adducts is also intensified $[9,10]$.

Homeostasis of the oxidoreductive system which is disturbed by electromagnetic waves, as well as the function of ion channels, are jointly responsible for the process of sperm hyperactivation. One of the factors inducting hyperactivation and capacitation is superoxide radical anion. Human sperm, in order to obtain the capability for fertilization of the egg cell, is subject to many metabolic changes concerning mainly the cellular membrane. This process is described as capacitation, and takes place in the female genital tract. As a result of capacitation, spermatozoons achieve the capability to interact with the structures of the corona radiata, and later with the zona pellucida of the ovulated oocyte. As a result of capacitation, there occurs modification of the path and movement of gametes, consisting in an increase in the amplitude and curvature of flagellar beat and induction of an intensified propelling strength, described as the state of hyperactive motility [10]. Hyperactivation of spermatozoons consists in a change in the way of their movement from symmetrical fine movements to asymmetrical flagellar beating. This process is indispensable for the transition of the spermatozoon through the zona pellucida of the ovum and fertilization. Premature capacitation taking place still in the seminal plasma causes energetic exhaustion of sperm and decreases the chance for fertilization. Homeostasis maintained in the oxidoreductive system is the factor responsible for the appropriate moment for capacitation [11]. The transition of this balance towards one side results in sperm damage, whereas transition towards the opposite side may trigger premature capacitation [12].

The transport of ions via cellular membrane of the spermatozoon regulates its maturation in the genital tract and decides about the capability for fertilizing the egg cell. Ionic channels are responsible for the normal course of these phenomena: CatSper, $\mathrm{pH}$-regulated, calcium-selective ion channel, KSper (Slo3), and voltage-gated channel Hv1. Todate it has been considered that many other channels regulate these processes; however, this has not been confirmed by proper measurements, and only the introduction of the patch-clamp technique shed new light on the possibilities of recognizing this phenomenon. Mutations and deletions of genes responsible for the functioning of these channels are also responsible for the occurrence of male infertility $[13,14]$.

The voltage-gated channel Hv1, which is the sensor of electric voltage responsible for the alkalization of the intracellular environment necessary in the process of capacitation, hyperactivation, acrosomal response and sperm motility, seems to be most vulnerable to electromagnetic waves $[15,16]$. Based on the results of studies concerning the effect of electromagnetic waves on cells of the immune system, it is known that the effect of EMR modifies the transport of $\mathrm{Ca}$ ions to the cell, and the wave frequency close to $15 \mathrm{~Hz}$ exerts the strongest effect on this phenomenon [17]. Thus, it may be expected that similar relationships will also concern sperm.

It has long been known that welding arcs are an especially hazardous source of radiation for men. Their radiation consists of an intensive thermal radiation from welding gases heated to a high temperature, welded or cut elements, electrode and flux material, on which there overlap lines and waves of radiation typical of these materials. The temperature of the flame of the gas welder generally does not exceed 2,000 K. Therefore, this radiation consists of mainly infrared and light, and only hydrogen and acetylene burners, characterized by a higher combustion temperature, may emit near ultraviolet light. In turn, the combustion temperature of an electric and plasma arc exceeds $4,000 \mathrm{~K}$, and with gas-shielded welding - it may reach even 30,000 $\mathrm{K}$. Thus, these appliances emit intensive blue light and ultraviolet radiation (UV), including short-wave ultraviolet. The intensity of irradiation within the UV spectrum at the distance from $0.7-1 \mathrm{~m}$ from the electric or plasma arc is from several to more than a dozen $\mathrm{W} / \mathrm{m}^{2}$, according to the type of electrode and welding conditions [18]. With respect to the analysis of intensities of electromagnetic fields around the electric arc generated by an inverter welder - within the range of intensities of industrial frequency of the field at the arc remain within the levels $1 \mathrm{~A} / \mathrm{m}$ and $30 \mathrm{~V} / \mathrm{m}$, and within the range of higher frequencies wide band measurement 50 $\mathrm{MHz}-3.5 \mathrm{GHz}$ shows the level of $0.3 \mathrm{~V} / \mathrm{m}$, and the character of the spectrum is very heterogenous and non-linear [19].

Scientific reports concerning the effect of welding on male fertility demonstrate that in men performing this occupation there occurs deterioration in semen parameters, and an increased percentage of miscarriages in their female partners. Spermatozoons of individuals exposed to welding have a decreased capability for penetrating into the egg cell. An evident epigenetic effect on the health of welders' children has not been confirmed. The intensification of hazardous effects on the male reproductive system depends on the type of materials welded, and concerns especially mild steel [20].

Exposure to intensive electromagnetic fields also concerns the operators of radar stations. At present, radars of various types operate within frequencies from $3 \mathrm{MHz}$ (HF band) - $110 \mathrm{GHz}$ (W band). Within the lower part of this range operate radars measuring the height of the ionosphere and radars using the phenomenon of reflection of electromagnetic waves in the ionosphere for the detection of objects hidden beyond the horizon, often at a distance of thousands of kilometers. Within the upper range of frequencies there operate laser radars, with bearing discrimination which allows determination of distances of individual targets on a battlefield. Nevertheless, the majority of radars work within the frequency range from several hundred megahertz to 100 $\mathrm{GHz}$ (including photoradars known to all drivers, which use the band $34.3 \pm 0.1 \mathrm{GHz}$ for taking photographs of drivers).

Reports concerning their effect on male fertility are contradictory. Ye et al. and Ding et al. describe an increase in the percentage of pathological sperm, and a decrease in semen motility, with the simultaneous lack of effect on its density among workers of radar stations [21, 22]. In turn, Weyandt T.B. et al. describe a decrease in sperm density in individuals exposed to radar waves [23]. However, Schrader S.M. et al. did not confirm any differences in the quality of sperm between men exposed to radar, and those not exposed to its effect [24]. The discrepancies obtained by the researchers with respect to the problem of the potential hazardous effect of radar waves on reproduction may result from the construction differences between the appliances emitting these waves.

A considerable exposure to electromagnetic waves also concerns men employed with high-voltage electric 
installations. Knave B. et al., while examining employees who had been exposed for many years to contact with the voltage of $400 \mathrm{kV}$, observed that a smaller number of children were conceived by these men, compared to the control group. Among children of individuals exposed to high voltage there also dominated the male gender. In turn, Nordström S. et al. found that among children of males exposed to high voltages, congenital defects occurred more frequently. Overhead highvoltage power lines generate electric and magnetic fields, which are not only analyzed with respect to occupational exposure, but also with respect to the environment. Based on the results of studies and in concern for human health and the state of the environment, standards and regulations have been introduced aimed at limiting the strength of electric and magnetic fields produced by overhead power lines. The intensity of these fields should be systematically monitored and analyzed, especially in inhabited areas.

The development of telecommunication technologies contributed to the fact that at present, almost every person is exposed to electromagnetic waves related with the mobile network $[25,26,27]$. Two mutually supplementary methods are used for the evaluation of human exposure to electromagnetic fields emitted by mobile network devices: measurements of physical human models - phantoms, and computer simulations. These methods are described as experimental dosimetry and numerical dosimetry, respectively. The advantage of the experimental approach is that it enables the examination of real devices, whereas the disadvantage is that material phantoms are very simple (homogenous) and do not pattern the strongly heterogenous internal construction of the human body (are constructed of a specialist gel, which does not pattern precisely the systems of tissues). Computer modeling is an improvement because these are precise anatomical human models which are used in numerical dosimetry. Due to these models, it is possible to trace the distribution of SAR in many parts of the body and in many tissues [28].

Studies conducted by Wdowiak A. et al, in parallel with Fejes et al., concerning the exposure to waves emitted by mobile phones in men, initiated scientific interest in this phenomenon [25, 29]. Own studies showed an increase in the percentage of pathological sperm which was more intensified with the duration of the time of exposure to GSM waves. The conducted studies also demonstrated a decrease in the percentage of sperm in progressive movement with an increase in exposure to the waves emitted by mobile phones. Studies concerning the effect of GSM technology on sperm were continued by Agarwal et al. and De Iuliis et al. $[9,26]$. They confirmed that the waves emitted by mobile phones cause the generation of reactive oxygen species (ROS), which may lead to the occurrence of oxidative stress in spermatozoons, and intensification of DNA fragmentation. Similar results of studies were later obtained by Liu C. et al. who investigated the sperm of mice [30]. In the study in which male mice were subjected to radiation of $900 \mathrm{~mW} / \mathrm{kg}$ 12 hours daily for 7 days, a considerable effect of EMR was observed on the integrity of mitochondrial genome [31]. It was also proved that long-lasting telephone conversations lead to small changes in the brain temperature, which may affect the activity of the hypothalamic-pituitary-testicular axis [32].

At the same time, there are scientific reports which confirm a beneficial effect of electromagnetic waves of lower frequencies range, both on the semen parameters and the functioning of tissues responsible for human reproduction. Examples of such reports are the studies by Falahati S.A. et al. and Łopucki M. et al. which showed that the exposure of sperm to electromagnetic waves within the range 10 $50 \mathrm{~Hz}$ contributes to improvement in the motility of human spermatozoons [33, 34]. Li D.K. et al. obtained different results with respect to $50 \mathrm{~Hz}$, while Tateno $\mathrm{H}$. et al., who investigated the occurrence of chromosomal aberrations in sperm exposed to a similar range of frequencies, did not find any differences between the control and study groups $[35,36]$. Formicki K. et al., while studying exposure of fish reproductive cells to the magnetic field, observed an improvement in the parameters of sperm movement, and an increased percentage of conceptions [37].

The results of studies confirming a beneficial effect of electromagnetic waves evoke hope for the application of these inventions in infertility treatment in humans; however, a longlasting effect of this type of energy will require scrupulous studies concerning especially the possible epigenetic effects found only in future generations.

Effect of EMR on the female reproductive system and pregnancy. In the case of the female reproductive system, electromagnetic waves exert an effect similar to that on the male reproductive system. The generation of oxidative stress affects the function of ion channels and the structure of proteins, and seems to be the major pathomechanisms of the effect of EMR on the oocyte, embryo, and the environment in which they develop. The thermal effect of electromagnetic waves seems to be important with respect to the functioning of the male testicles; however, this is rather omitted in the case of the ovaries.

Considering the technical and bioethical limitations related with the obtaining of an oocyte, the available reports concerning the effect of EMR on its functions are mainly based on animal models. Gul et al., during exposure of female rats to the frequency of $900 \mathrm{MHz}$, observed a decrease in the number of ovulatory follicles produced [38]. During studies carried out on rat oocytes, Roshangar L. et al. demonstrated that oocytes in the group exposed to EMR showed shrinking of the nucleus, and their zona pellucida seemed thinner, compared to the oocytes from the control group [39]. The number of microvilli was considerably decreased, drops of lipids were observed in their cytoplasm, and the cell organellae were dispersed. In the granular cells and the cells of the corona radiata collected from rats exposed to contact with the waves, the signs of apoptosis were observed, such as: condensation of the nucleus, chromatin marginalization, and dilatation of the nuclear membrane. Basic morphological changes found in granular cells consisted in their shrinking, atrophy of the microvilli, and atrophy or condensation of the cristas. Mailhes J. B. et al. also observed that the placement of a mouse oocyte in an electromagnetic field causes multiplication of the double system of chromosomes [40].

Panagopoulos D.J. et al. evaluated the effect of electromagnetic waves related with the GSM network on reproductive cells of flies, and observed an intensification of DNA fragmentation in the nucleus and features of apoptosis in the egg cells placed in EMF [41]. Similar conclusions concerning the problem of acceleration of apoptosis of a mouse oocyte were drawn by Sagioglou N.E. et al. [42]. Experiments conducted by Fedorov A. et al. on a similar animal model 
showed that a mature oocyte is most vulnerable to damage, while its earlier developmental stages are vulnerable to a lower degree [43].

Studies carried out by Guney et al. on rats exposed to the frequency $900 \mathrm{MHz}$ proved that these ranges of waves cause the occurrence of oxidative stress leading to an inflammatory state of the endometrium [44]. These studies demonstrated that among irradiated rats a decrease was noted in the endometrial superoxide dismutase (SOD) and catalase, and this phenomenon may be inhibited by the supplementation of vitamins $\mathrm{C}$ and $\mathrm{E}$.

Iaremchuk M. M. et al. investigated fish embryos placed in similar frequencies of radio waves and observed an initial increase in the SOD activity, followed by its subsequent considerable decrease below the values observed in the control group [45]. These studies also showed that the content of the products of peroxidation of lipids of reproductive cells is subject to significant changes under the effect of low intensity of electromagnetic radiation.

Studies by Wdowiak A. et al. indicated that in a woman's body the activity of SOD and catalase affects the quality of embryos and the dynamics of their development [46]. This allows the presumption that an analogous exposure of a human body to these wave ranges may cause reproductive disorders at the stages from conception to the blastocyte stage, and the implantation process.

The effect of the frequency of $50 \mathrm{~Hz}$ on mouse embryos was described by Borhani N. et al. [47]. They showed an intensification of DNA fragmentation in blastomers, as well as a decreased percentage of blastocysts among embryos placed in this field. In turn, Delgado J. M. et al. compared the effect of the frequencies of electromagnetic fields of $10 \mathrm{~Hz}$, $100 \mathrm{~Hz}$ and $1 \mathrm{kHz}$ on the development of hen embryos [48]. Teratogenic effect concerned the ranges 100 to $1,000 \mathrm{~Hz}$, whereas exposure to $10 \mathrm{~Hz}$ did not exert any effect on embriogenesis. However, studies by Di Carlo A. L. et al. on a similar model confirmed that the frequency of $60 \mathrm{~Hz}$ protects hen embryos against hypoxia [49].

Lim J. H. et al found a beneficial effect of EMF exerted by the frequencies $10 \mathrm{~Hz}$ and $50 \mathrm{~Hz}$ on the culture of stem cell lines collected from swine [50]. A similar phenomenon was observed by Liu C. et al. in the case of cell culture lines of mesenchymal cells of rat bone marrow stroma [51]. Proliferation of these cells was considerably elevated in the group exposed to the $10 \mathrm{~Hz}$ wave. In addition, it was found that the mineralization of the extracellular matrix was intensified in the case of irradiation of the tissue with the $\mathrm{Hz}$ wave. These results demonstrated that exposure to various frequencies had different positive effects for viability, proliferation and osteogenic differentiation.

The frequencies of waves up to $20 \mathrm{~Hz}$ have a therapeutic effect in physiotherapy. A review of literature performed by Shah S. G. et al. concerning the course of pregnancy in women performing occupational activity in such fields, did not confirm any effect on its course [52]. Analysis of available reports pertaining to the effect of frequencies related with the mobile network and Wi-Fi performed by Nazıroğlu M. et al., emphasized risk related with the occurrence of miscarriages and the lack of other effects on the foetus in pregnant women exposed to these frequencies [53]. Own studies concerning the use of mobile phones during pregnancy showed that the state of the newborn evaluated directly after delivery according to the APGAR scale, was worse in women exposed to a greater degree to the waves of the GSM band [54]. An explanation of this phenomenon may be sought in the effect exerted by electromagnetic waves on the placental functions.

Analysis performed by Łopucki M. et al. concerning the frequency $50 \mathrm{~Hz}$ revealed that EMR in this band causes unfavourable morphological changes in the placental tissues, pertaining to the nuclei, cytoplasm and cellular membranes [55]. The researchers also observed a decreased oxygen use, and intensification of apoptosis in the cells of the placenta exposed to these wave ranges [56]. Łopucki et al. also found that the placental tissue in EMF increased the secretion of calcium ions, which might suggest the effect of EMF on the function of calcium channels described in other tissues $[17,57]$.

\section{CONCLUSIONS}

At present, the hazardous, neutral or beneficial effects of electromagnetic waves on human reproductive capabilities cannot be generalized. It may be expected that there are doses of energy which exert a neutral or positive effect, and only exceeding them may cause hazardous effects. The existing scientific reports provide insufficient evidence for expressing ultimate comments concerning the amount and form of energy transmitted in the form of an electromagnetic wave which creates risk for humans. Therefore, it is more important to undertake studies monitoring the value of the intensity of the fields, and perform numerical analyses of energy absorption.

Models of studies conducted on animals cannot be directly referred to humans, because the cellular membranes of the reproductive tissues are species are variable. Despite this, both in the case of studies concerning humans and animals, the phenomenon is observed of a higher probability of the occurrence of various types of health risk with exposure to increasingly higher frequencies of electromagnetic waves.

\section{REFERENCES}

1. Zmyślony M, Politański P. Zagrożenia zdrowia i ochrona zdrowia pracujących w narażeniu na pola i promieniowanie elektromagnetyczne 0-300 GHz. Oficyna Wydawnicza Instytutu Medycyny Pracy im. prof. J. Nofera, 2009; 7-50 (in Polish).

2. Sheppard AR, Swicord ML, Balzano Q. Quantitative evaluations of mechanisms of radiofre- quency interactions with biological molecules and processes. Health Phys. 2008; 95(4): 365-96.

3. Challis LJ. Mechanisms for interaction between RF fields and biological tissue. Bioelectromagnetics. 2005; Suppl 7: 98-106.

4. Kotnik T, Miklavcic D. Theoretical evaluation of voltage inducement on internal membranes of biological cells exposed to electric fields. Biophys J. 2006; 90(2): 480-91.

5. Seger R, Friedman J, Kraus S, Hauptman Y, Schiff Y. Mechanism of short-term ERK activation by electromagnetic fields at mobile phone frequencies. Biochem J. 2007; 405: 559

6. Porcelli M, Cacciapuoti G, Fusco S, Massa R, d'Ambrosio G, Bertoldo C, De Rosa M, Zappia V.Non-thermal effects of microwaves on proteins: thermophilic enzymes as model system. FEBS Lett. 1997; 402(2-3): 102-6.

7. De Pomerai DI, Smith B, Dawe A, North K, Smith T, Archer DB, Duce IR, Jones D, Candido EP. Microwave radiation can alter protein conformation without bulk heating. FEBS Lett. 2003; 543(1-3): 93-7.

8. Mancinelli F, Caraglia M, Abbruzzese A, d'Ambrosio G, Massa R, Bismuto E. Non-thermal effects of electromagnetic fields at mobile phone frequency on the refolding of an intracellular protein: myogl. J Cell Biochem. 2004; 93(1): 188-96. 
9. Agarwal A, Desai NR, Makker K, et al. Effects of radiofrequency electromagnetic waves (RF-EMW) from cellular phones on human ejaculated semen: an in vitro pilot study. Fertil Steril. 2009; 92(4): $1318-25$.

10. Makker K, Varghese A, Desai NR, Mouradi R, Agarwal A. Cell phones: modern man's nemesis? Reprod Biomed Online. 2009; 18(1): 148-57.

11. Szkodziak P, Wozniak S, Czuczwar P, Wozniakowska E, Milart P, Mroczkowski A, Paszkowski T. Infertility in the light of new scientific reports - focus on male factor. Ann Agric Environ Med. 2016; 23(2): 227-30.

12. Bojar I, Witczak M, Wdowiak A. Biological and environmental conditionings for a sperm DNA fragmentation. Ann Agric Environ Med. 2013; 20(4): 865-8

13. Lishko PV, Kirichok Y, Ren D, Navarro B, Chung JJ, Clapham DE. The control of male fertility by spermatozoan ion channels. Annu Rev Physiol. 2012

14. Darszon A, Nishigaki T, Beltran C, Treviño CL. Calcium channels in the development, maturation, and function of spermatozoa. Physiol Rev. 2011; 91(4): 1305-55.

15. DeCoursey TE. Voltage-gated proton channels: molecular biology, physiology, and pathophysiology of the $\mathrm{H}(\mathrm{V})$ family. Physiol Rev. 2013; 93(2): 599-652.

16. Okamura Y, Fujiwara Y, Sakata S. Gating mechanisms of voltage-gated proton channels. Annu Rev Biochem. 2015; 84: 685-709.

17. Walleczek J. Electromagnetic field effects on cells of the immune system the role of calcium signaling. FASEB J. 1992 Oct; 6(13): 3177-3185.

18. Wolska A, Marzec S, Owczarek G. Zasady higienicznej oceny promieniowania optycznego, CIOP Warszawa 2001 (in Polish).

19. Mazurek PA, Wac-Włodarczyk A, Filipek P, Serwin S, Błażejewska A. Ocena przewodzonych zagrożeń elektromagnetycznych prototypowej spawarki inwertorowej, Przegląd Elektrotechniczny 2012; 12b; 198-200 (in Polish).

20. Bonde JP. The risk of male subfecundity attributable to welding of metals. Studies of semen quality, infertility, fertility, adverse pregnancy outcome and childhood malignancy. Int J Androl. 1993; 16 Suppl 1: $1-29$.

21. Ye LL, Suo YS, Cao WL, Chen M. Radar radiation damages sperm quality. Zhonghua Nan Ke Xue. 2007; 13(9): 801-3.

22. Ding XP, Yan SW, Zhang N, Tang J, Lu HO, Wang XL, Tang Y. A crosssectional study on nonionizing radiation to male fertility. Zhonghua Liu Xing Bing Xue Za Zhi. 2004; 25(1): 40-3.

23. Weyandt TB, Schrader SM, Turner TW, Simon SD. Semen analysis of military personnel associated with military duty assignments. Reprod Toxicol. 1996; 10(6): 521-8.

24. Schrader SM, Langford RE, Turner TW, Breitenstein MJ, Clark JC, Jenkins BL, Lundy DO, Simon SD, Weyandt TB. Reproductive function in relation to duty assignments among military personnel. Reprod Toxicol. 1998; 12(4): 465-8.

25. Wdowiak A, Wdowiak L, Wiktor H. Evaluation of the effect of using mobile phones on male fertility. Ann Agric Environ Med. 2007; 14(1): 169-72.

26. De Iuliis GN, Newey RJ, King BV, Aitken RJ. Mobile phone radiation induces reactive oxygen species production and DNA damage in human spermatozoa in vitro. PLoS One 2009; 4(7): e644622.

27. Mazurek PA, Kisiel K, Tomczyk P, Wiak M. Analiza emisji elektromagnetycznej w środowisku przemysłowym na przykładzie Zakładów Azotowych Puławy S.A. Przegląd Elektrotechniczny 2014; 12(90); 240-243 (in Polish).

28. Zmyślony M. Mechanizmy biologiczne i efekty zdrowotne PEM w świetle wymagań raportu oddziaływaniu obiektu na środowisko. Med Pr. 2007; 58(1): 27-36 (in Polish).

29. Fejes I, Zavaczki Z, Szollosi J, et al. Is there a relationship between cell phone use and semen quality? Arch Androl. 2005; 51(5): 385-93.

30. Liu C, Duan W, Xu S, Chen C, He M, Zhang L, Yu Z, Zhou Z. Exposure to $1800 \mathrm{MHz}$ radiofrequency electromagnetic radiation induces oxidative DNA base damage in a mouse spermatocyte-derived cell line. Toxicol Lett. 2013; 218(1): 2-9.

31. Aitken RJ, Bennetts LE, Sawyer D, Wiklendt AM, King BV. Impact of radio frequency electromagnetic radiation on DNA integrity in the male germline. Int J Androl. 2005; 28(3):171-9.

32. Izmest'eva OS, Parshkov EM, Zhavoronkov LP, Izmest'ev VI, Litovkina LV, Voron'ko IaV. Effects of electromagnetic field of thermal intensity on the hypophysis-thyroid unit of the neuroendocrine system. Radiats Biol Radioecol. 2003; 43(5): 597-600.

33. Falahati SA, Anvari M, Khalili MA. Effect of combined magnetic fields on human sperm parameters. Iran. J. Radiat. Res. 2011; 9(3): 195-200.

34. Łopucki M, Jakiel G, Bakalczuk S, Pietruszewski M, Kankofer J. Influence of alternating magnetic field with magnetic induction $0.5 \mathrm{mT}$ and frequency $50 \mathrm{~Hz}$ on human spermatozoa in-vitro. Int J Androl. 2005; 28(suppl. 1): 106, Abstr. of the 8th International Congress of Andrology. Seoul, 12-16 June 2005.
35. Li DK, Yan B, Li Z, Gao E, Miao M, Gong D, Weng X, Ferber JR, Yuan W. Exposure to magnetic fields and the risk of poor sperm quality. Reprod Toxicol. 2010; 29(1): 86-92.

36. Tateno H, Iijima S, Nakanishi Y, Kamiguchi Y, Asaka A. No induction of chromosome aberrations in human spermatozoa exposed to extremely low frequency electromagnetic fields. Mutat Res. 1998; 414(1-3): 31-5.

37. Formicki K, Szulc J, Tański A, Korzelecka-Orkisz A, Witkowski A, Kwiatkowski P. The effect of static magnetic field on Danude huchen,Hucho hucho(L.)sperm motility parameters. Arch Pol Fish. 2013; 21: 189-197.

38. Gul A, Celebi H, Uğraş S. The effects of microwave emitted by cellular phones on ovarian follicles in rats. Arch Gynecol Obstet. 2009; 280(5): 729-33.

39. Roshangar L, Hamdi BA, Khaki AA, Rad JS, Soleimani-Rad S. Effect of low-frequency electromagnetic field exposure on oocyte differentiation and follicular development. Adv Biomed Res. 2014; 3: 76.

40. Mailhes JB, Young D, Marino AA, London SN. Electromagnetic fields enhance chemically-induced hyperploidy in mammalian oocytes. Mutagenesis. 1997; 12(5): 347-51.

41. Panagopoulos DJ, Chavdoula ED, Nezis IP, Margaritis LH. Cell death induced by GSM $900-\mathrm{MHz}$ and DCS $1800-\mathrm{MHz}$ mobile telephony radiation. Mutat Res. 2007; 626(1-2): 69-78.

42. Sagioglou NE, Manta AK, Giannarakis IK, Skouroliakou AS, Margaritis LH. Apoptotic cell death during Drosophila oogenesis is differentially increased by electromagnetic radiation depending on modulation, intensity and duration of exposure. Electromagn Biol Med. 2015: 1-14.

43. Fedorov AI, Weǐsman NIa, Nemova EF, Mamrashev AA, Nikolaev NA. Terahertz radiation influence on number and development dynamics of offspring F1 of fruit fly females under stress. Biofizika. 2013; 58(6): 1043-50.

44. Guney M, Ozguner F, Oral B, Karahan N, Mungan T. 900 MHz radiofrequency-induced histopathologic changes and oxidative stress in rat endometrium: protection by vitamins $\mathrm{E}$ and $\mathrm{C}$. Toxicol Ind Health. 2007; 23(7): 411-20.

45. Iaremchuk MM, Dyka MV, Sanahurs'kyĭ DI. The activity of prooxidantantioxidant system in loach embryos under the action of microwave radiation. Ukr Biochem J. 2014; 86(5): 142-50.

46. Wdowiak A, Wdowiak A. Comparing antioxidant enzyme levels in follicular fluid in ICSI-treated patients. Gynecol Obstet Fertil. 2015; 43(7-8): 515-21.

47. Borhani N., Rajaei F, Salehi Z, Javadi A. Analysis of DNA fragmentation in mouse embryos exposed to an extremely low-frequency electromagnetic field. Electromagn Biol Med. 2011; 30(4): 246-52.

48. Delgado JM, Leal J, Monteagudo JL, Gracia MG. Embryological changes induced by weak, extremely low frequency electromagnetic fields. Jurn Anat. 1982; 134(Pt 3): 533-51.

49. Di Carlo AL, Mullins JM, Litovitz TA. Thresholds for electromagnetic field-induced hypoxia protection: evidence for a primary electric field effect. Bioelectrochemistry. 2000; 52(1): 9-16.

50. Lim JH, McCullen SD, Piedrahita JA, Loboa EG, Olby NJ. Alternating current electric fields of varying frequencies: effects on proliferation and differentiation of porcine neural progenitor cells. Cell Reprogram. 2013; 15(5): 405-12.

51. Liu C, Yu J, Yang Y, Tang X, Zhao D, Zhao W, Wu H. Effect of 1 $\mathrm{mT}$ sinusoidal electromagnetic fields on proliferation and osteogenic differentiation of rat bone marrow mesenchymal stromal cells. Bioelectromagnetics. 2013; 34(6): 453-64.

52. Shah SG, Farrow A. Systematic literature review of adverse reproductive outcomes associated with physiotherapists occupational exposures to non-ionising radiation. J Occup Health. 2014; 56(5): 323-31.

53. Nazıroğlu M Yüksel M, Köse SA Özkaya MO. Recent reports of $\mathrm{Wi}-\mathrm{Fi}$ and mobile phone-induced radiation on oxidative stress and reproductive signaling pathways in females and males. J Membr Biol. 2013; 246(12): 869-75.

54. Wdowiak A, Lewicka M, Sulima M, Kais A, Stec M, Skrzypczak M, Sawicki K, Kapka-Skrzypczak L, Praca przy komputerze i korzystanie $\mathrm{z}$ telefonu komórkowego a dobrostan noworodka. Probl Hig Epidemiol 2012; 93(4): 698-701 (in Polish).

55. Łopucki M, Łańcut M, Rogowska W, Czerny K, Jedrych B, Pietruszewski S, Kornarzyński K, Kotarski J. Evaluation of the morphology of the human placental cotyledon following dual in vitro perfusion in variable magnetic field. Ginekol Pol. 2003; 74(10): 1187-93.

56. Łopucki M, Rogowska W, Pietruszewski S, Kornarzyński K, Kowalski P, Kotarski J. Oxygen transfer and consumption in human placenta exposed to variable magnetic fields in vitro. Ginekol Pol. 2004; 75(3): 177-86.

57. Łopucki M, Czekierdowski A, Rogowska W, Kotarski J. The effect of oscillating low intensity magnetic field on the $\mathrm{Na}+\mathrm{K}+, \mathrm{Ca}++$, and $\mathrm{Mg}++$ concentrations in the maternal and fetal circulation of the dually perfused human placental cotyledon. Bioelectromagnetics. 2004; 25(5): 329-37. 